\title{
Relationship between nutritional status and frailty in hospitalized older patients
}

This article was published in the following Dove Medical Press journal: Clinical Interventions in Aging

\author{
Xiufang Hong ${ }^{1,2}$ \\ Jing Yan' \\ Liyu Xu' \\ Shanshan Shen' \\ Xingkun Zeng' \\ Lingyan Chen'
}

'Department of Geriatrics, Zhejiang Hospital, Hangzhou 3 I00 I 3, People's Republic of China; ${ }^{2}$ The Second School of Medicine, Zhejiang Chinese Medical University, Hangzhou 310053 ,

People's Republic of China
Correspondence: Jing Yan Department of Geriatrics, Zhejiang Hospital, Lingyin Road \#12, Hangzhou 3100 I3, People's Republic of China $\mathrm{Tel}+8613336188688$

Fax+86 57I 8798 0175 Email zjicu@vip.163.com
Objective: The definition of frailty still lacks quantitative biomarkers. This study aimed to investigate the relationship between nutrition-related biomarkers and frailty in hospitalized older patients.

Materials and methods: This is a cross-sectional study including 380 hospitalized older patients. The patients were categorized as nonfrail $(n=140)$, prefrail $(n=81)$, and frail $(n=159)$ by the criteria of frailty phenotype. The nutritional status was assessed using the mini nutritional assessment-short form (MNA-SF), levels of serum transferrin (TNF), prealbumin (PA), total protein (TP), albumin (ALB), retinol-binding protein (RBP), and hemoglobin ( $\mathrm{Hb}$ ).

Results: The grip strength, levels of serum TFN, TP, ALB, Hb, and MNA-SF scores all decreased significantly in the order of nonfrail, prefrail, and frail groups $(P<0.01)$. Older ages, more fall incidents, and higher polypharmacy ratio were observed in the frail and prefrail groups than in the nonfrail group $(P<0.05)$. Univariate logistic regression analysis showed that frailty was positively related to age, polypharmacy, fall history, nutritional status, levels of TFN, PA, $\mathrm{TP}, \mathrm{ALB}, \mathrm{RBP}$, and $\mathrm{Hb}$, but was negatively related to grip strength. Ordinal logistic regression analysis showed that older patients who were well nourished, with higher levels of TFN, TP, and ALB were less likely to develop into frailty.

Conclusion: Hospitalized older patients with better nutritional status and higher levels of TFN, TP, and ALB were less likely to develop into frailty. These nutrition-related biomarkers may be used for the evaluation of nutritional status and frailty in older patients.

Keywords: frailty, nutrition, malnutrition, frailty phenotype, elderly

\section{Introduction}

Frailty is a geriatric syndrome and is commonly defined as a clinically recognizable state in older adults. It is associated with increased vulnerability that is resulted from aging-associated declines in physiologic reserve and function across multiple organs and systems. ${ }^{1-5}$ Frailty is highly prevalent with increasing age and gives rise to high risk for adverse health outcomes, including falls, hospitalization, and mortality.

The concept and definition of frailty is still evolving. One of the approaches to frailty is the frailty phenotype, ${ }^{3}$ which contains unintentional weight loss, exhaustion, weakness, slowness, and low physical activity. It is estimated that $10 \%-27 \%$ of the population over 65 years is frail by the definition of a combination of any three phenotypes. ${ }^{6}$ Another approach defines frailty as a stage of age-related deficit accumulation and quantify the frail state using a "frail index", which is the ratio of present deficits to the ones evaluated. ${ }^{7}$ Both approaches to frailty have been extensively used and adapted in animal studies and clinical trials. Due to the lack of subcellular mechanisms and effective biomarkers, a consensus has not been reached in the concept of frailty. 
Malnutrition is very common in hospitalized older patients with a prevalence up to $50 \% .{ }^{8,9}$ Poor nutritional status has been shown to be associated with adverse clinical outcomes in older patients, such as decreased physical functions and increased mortality. ${ }^{10,11}$ In recent years, the relationship between frailty and malnutrition in community-dwelling older people has been demonstrated. ${ }^{12-15}$ However, this relationship in hospitalized older patients has not been investigated.

Our study aimed to compare the nutritional status and physical functions between nonfrail, prefrail, and frail hospitalized older patients and identify possible biomarkers for the evaluation of nutritional status and frailty.

\section{Materials and methods}

\section{Study design}

This is a cross-sectional study analyzing the clinical data of hospitalized older patients treated at the geriatric ward of Zhejiang Hospital between January 2017 and June 2018. The inclusion criteria were as follow: age $\geq 65$ years, ability to understand and communicate in Chinese, ability to walk without assistance except walking aids, and hearing and vision sufficient for compliance with assessment. The exclusion criteria were as follow: acute infection, malignant tumor, cerebellum diseases, acute cerebrovascular diseases, delirium, terminal illness, or severe cognitive impairment (Mini-Mental State Examination $[\mathrm{MMSE}]<12$ ). A total of 380 patients were included in the final analysis (Figure 1). Our study was conducted in accordance with the Declaration of Helsinki and was approved by the Research Ethics Committee of Zhejiang Hospital. Written informed consent was obtained from each participant.

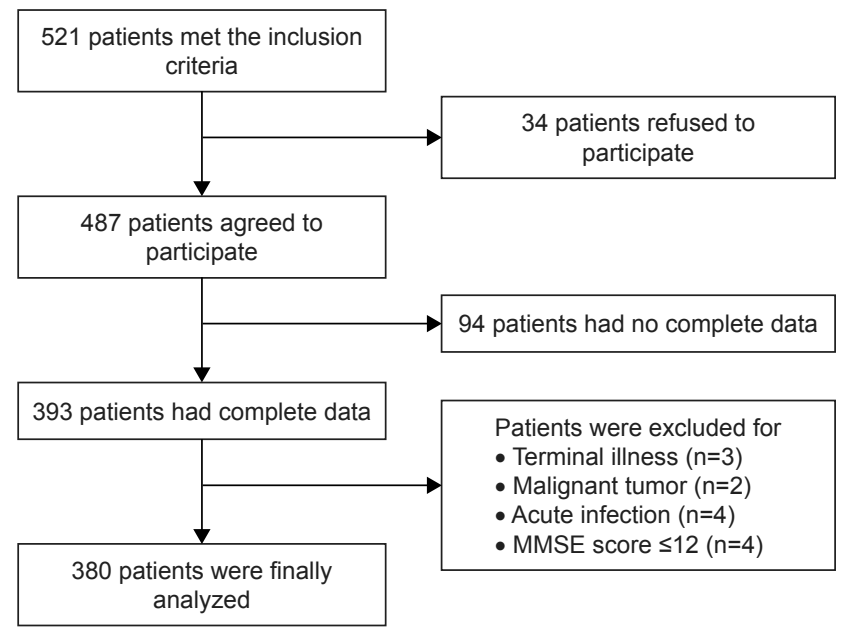

Figure I Flowchart of the patient inclusion. Abbreviation: MMSE, Mini-Mental State Examination.

\section{Patient assessment}

A comprehensive geriatric assessment (CGA) and frailty assessment were given to each qualified patient by a geriatric nurse and a geriatrician in our ward within 3 days after admission. The main content of CGA includes a general health questionnaire, assessment of activities of daily living (ADL), ${ }^{16}$ instrumental ADL (IADL) $,{ }^{17} \mathrm{MMSE},{ }^{18}$ mini nutritional assessment-short form (MNA-SF), ${ }^{19}$ and Tinetti performance-oriented mobility assessment (POMA). ${ }^{20}$ Grip strength, fall history in the past year, and polypharmacy were recorded. Serum levels of transferrin (TFN), prealbumin (PA), total protein (TP), albumin (ALB), retinol-binding protein $(\mathrm{RBP})$, and hemoglobin $(\mathrm{Hb})$ were measured and recorded. Sociodemographic data including age, gender, educational level, body weight, and height were collected.

\section{Assessment of frailty status}

The Fried criterion, also known as the frailty phenotype, was used to assess the frailty status. Frailty phenotype with the five items is the most extensively used and tested criteria for its validity. These criteria are mentioned below.

- Unintentional weight loss over $4.5 \mathrm{~kg}$ or $5 \%$ of body weight during the last year.

- Decrease in the grip strength measured by Jamar dynamometer. The patient is sitting in the chair with the shoulders adducted, the elbows flexed to $90^{\circ}$, and the forearms in neutral position. Three measurements are made with 1-minute intervals, and the mean value of the three measurements is calculated. All values are adjusted for gender and body mass index (BMI). The criteria for weakness in women are the strength $\leq 17 \mathrm{~kg}$ for BMI of $\leq 23, \leq 17.3 \mathrm{~kg}$ for BMI between 23.1 and $26, \leq 18 \mathrm{~kg}$ for BMI between 26.1 and 29 , and $\leq 21 \mathrm{~kg}$ for BMI $>29$. For men, the adjusted values are $\leq 29 \mathrm{~kg}$ for BMI of $\leq 24, \leq 30 \mathrm{~kg}$ for BMI between 24.1 and 26, $30 \mathrm{~kg}$ for BMI between 26.1 and 28 , and $\leq 32 \mathrm{~kg}$ for BMI $>28$.

- Self-reported exhaustion. Self-reported feeling that everything is an effort or that one could not get "going" $>2$ times a week.

- Slow walking speed. It is also adjusted for gender and the height of the patient regardless of whether a walking aid is used or not. For men with a height $\leq 173 \mathrm{~cm}, \geq 7$ seconds of walking through a distance of $4.57 \mathrm{~m}$ and for men with a height $>173 \mathrm{~cm}, \geq 6$ seconds are assumed as slow speed. For women, slow speed is $\geq 7$ seconds for those with a height $\leq 159 \mathrm{~cm}$ and $\geq 6$ seconds for those with a height $>159 \mathrm{~cm}$ (distance is same in all cases). 
- Low physical activity level. The criteria are $<383 \mathrm{kcal} /$ week for men and $<270 \mathrm{kcal} /$ week for women. All participants were diagnosed according to the frailty phenotype. One point for each item: $0=$ not frail; $1-2=$ prefrail; $\geq 3=$ frail.

\section{Assessment of nutritional status}

The MNA-SF was used for the assessment of nutritional status, which has been validated for malnutrition screening in frail older people. ${ }^{21}$ The MNA-SF includes six items: 1) weight loss in the last 3 months: $>3 \mathrm{~kg}=0$, unknown $=1,1-3 \mathrm{~kg}=2$, no $=3 ; 2$ ) BMI: $<19=0,19-21=1$, $21-23=2,>23=3 ; 3$ ) psychological stress or acute disease: no $=0$, yes $=2 ; 4$ ) mobility: long-term bedridden $=0$, capability but unwillingness of activities $=1$, outdoor activities $=2 ; 5$ ) neuropsychological problems: severe dementia or depression $=0$, mild dementia or depression $=1$, no $=2$; 6) food intake: significant decrease in food intake $=0$, mild decrease in food intake $=1$, no $=2$. The maximum total score is 14 points. A total score of $12-14$ points indicate well nourishment, 8-11 points indicate risk of malnutrition, and 0-7 points indicate malnourishment.

\section{Data collection}

Sociodemographic data including age, gender, educational level, weight, and height were collected. Information about the frailty status and medication was collected by reviewing the medical records. Polypharmacy was defined as not less than five kinds of oral prescription drugs. ${ }^{22}$ The ADL, IADL, and POMA were used to assess functional status. The cognitive status was evaluated using the MMSE. The MNA-SF and levels of serum TFN, PA, TP, ALB, RBP, and $\mathrm{Hb}$ were used to assess the nutritional status. Venous blood samples were collected in the early morning from the fasting patients and tested in a laboratory of Zhejiang Hospital. Some categorical variables, such as gender, educational level, polypharmacy, fall history, frailty status, and nutritional status, were reassigned. Continuous variables such as TFN, $\mathrm{PA}, \mathrm{TP}, \mathrm{ALB}, \mathrm{RBP}$, and $\mathrm{Hb}$ were reassigned into three grades with a cutoff from the lowest value to the percentile 25 , the percentile 25 to the percentile 75 , and the percentile 75 to the highest value (Table S1).

\section{Statistical analysis}

The normally distributed continuous data were presented as mean and SDs, and the nonnormally distributed continuous data were presented as medians and IQR. Categorical variables were presented as percentages or constituent ratios. When three groups were considered, the one-way ANOVA test (for normally distributed continuous data), the Pearson's chi-squared test (for categorical data), and the Kruskal-Wallis test (for nonnormally distributed continuous data) were used for the comparison. When two groups were considered, the least significant difference (LSD) $t$-test (for normally distributed continuous data), the chi-squared test (for categorical data), and the Mann-Whitney $U$-test (for nonnormally distributed continuous data) were used for the comparison. As a secondary analysis, binary classification of frailty (nonfrail vs prefrail/frail) was treated as the dependent variable, and other assessments were treated as the continuous variables. The relationship between frailty and risk factors was analyzed using the univariate logistic regression analysis. Ordinal logistic regression analysis was used for further analysis of the relationship between frailty status and nutritional status as well as nutrition-related biomarkers, adjusting age, gender, BMI, polypharmacy, fall history, and grip strength. ORs were reported for significant associations. All statistical analyses were performed using the SPSS 22.0 software (IBM Corporation, Armonk, NY, USA). All significance tests were two-tailed, and statistical significance was assumed as $P<0.05$.

\section{Results}

Our patients included 140 nonfrail patients (36.8\%), 81 prefrail patients $(21.3 \%)$, and 159 frail patients $(41.9 \%)$. The grip strength, levels of serum TFN, TP, ALB, Hb, and scores of MNA-SF, ADL, IADL, MMSE, POMA decreased significantly in the order of nonfrail, prefrail, and frail groups $(P<0.01)$. Patients in the prefrail and frail groups were significantly older, more likely to have falls in the past year and had significantly higher polypharmacy rate in comparison with the nonfrail patients $(P<0.05$, Table 1$)$.

The risk factors that may be associated with frailty were analyzed using the univariate logistic regression analysis. The results showed that the frailty status was positively related to age, polypharmacy, fall history, nutritional status, levels of TFN, PA, TP, ALB, RBP, and $\mathrm{Hb}$, but was negatively related to grip strength (Table 2). Ordinal logistic regression analysis showed that older patients who were well nourished and had higher levels of TFN, TP, and ALB were less likely to develop into frailty (Table 3 ).

\section{Discussion}

Our study demonstrated that older hospitalized patients with better nutritional status and higher serum levels of TFN, TP, and ALB were less likely to develop into frailty. In the order of nonfrail, prefrail, and frail groups, the patients were older, with decreased grip strength, scores of ADL, IADL, MMSE, POMA, MNA-SF, higher rates of polypharmacy, 
Table I Comparison of patients' characteristics based on frailty status

\begin{tabular}{|c|c|c|c|c|}
\hline Characteristics & Nonfrailty $(n=\mid 40)$ & Prefrailty $(n=8 I)$ & Frailty $(n=159)$ & $P$-value \\
\hline \multicolumn{5}{|l|}{ Demographic } \\
\hline Age (years) & $77.69 \pm 7.67$ & $85.43 \pm 6.21 *$ & $86.75 \pm 5.80^{4}$ & $<0.001^{a}$ \\
\hline Male (\%) & $51(57.9)$ & $43(53.1)$ & $93(58.5)$ & $0.710^{\mathrm{b}}$ \\
\hline BMI $\left(\mathrm{kg} / \mathrm{m}^{2}\right)$ & $23.60 \pm 3.13$ & $23.33 \pm 4.56$ & $23.39 \pm 4.11$ & $0.857^{\mathrm{a}}$ \\
\hline Educational level (high/middle/low) (\%) & $30.7 / 47.1 / 22.1$ & $29.6 / 49.4 / 21.0$ & $34.6 / 47.2 / 18.2$ & $0.582^{b}$ \\
\hline \multicolumn{5}{|l|}{ Medical } \\
\hline Cardiovascular disease (\%) & $78(55.7)$ & $45(55.5)$ & $90(56.6)$ & $0.173^{b}$ \\
\hline Cerebrovascular disease (\%) & $33(23.6)$ & $18(22.2)$ & $30(18.8)$ & $0.102^{\mathrm{b}}$ \\
\hline Diabetes (\%) & $15(10.7)$ & $10(12.3)$ & $19(11.9)$ & $0.093^{b}$ \\
\hline Fall history (\%) & $19(13.6)$ & $17(21.0)$ & $44(27.7)^{\Delta}$ & $0.01 \mathrm{I}^{\mathrm{b}}$ \\
\hline Grip strength (kg) & $30.76 \pm 8.86$ & $22.8 \mathrm{I} \pm 7.30 *$ & $21.36 \pm 7.58^{\Delta, \#}$ & $<0.00 I^{a}$ \\
\hline Polypharmacy (\%) & $50(35.7)$ & $54(66.7)^{*}$ & $118(74.2)^{\Delta}$ & $<0.00 \mathrm{I}^{\mathrm{b}}$ \\
\hline MNA-SF & $13(12-14)$ & $12(11-14)^{*}$ & II $(10-13)^{\Delta, \#}$ & $<0.001^{\mathrm{c}}$ \\
\hline ADL & $100(100-100)$ & $100(95-100)$ & $90(75-100)^{\Delta, \#}$ & $<0.00 \mathrm{I}^{\mathrm{c}}$ \\
\hline IADL & $8(8-8)$ & $7(5-8)^{*}$ & $3(2-5)^{\Delta, \#}$ & $<0.00 \mathrm{I}^{\mathrm{c}}$ \\
\hline MMSE & 27 (25-29) & $25(22-27)^{*}$ & $23(18-27)^{\Delta}$ & $<0.001^{c}$ \\
\hline POMA & $26(25-28)$ & $21(17-24)^{*}$ & $18(15-23)^{\Delta, \#}$ & $<0.00 I^{c}$ \\
\hline \multicolumn{5}{|l|}{ Serum biomarkers } \\
\hline TFN (g/L) & $2.37 \pm 0.30$ & $2.08 \pm 0.28^{*}$ & $2.06 \pm 0.26^{\Delta}$ & $<0.00 \mathrm{I}^{\mathrm{a}}$ \\
\hline $\mathrm{PA}(\mathrm{mg} / \mathrm{L})$ & $237.89 \pm 47.56$ & $201.91 \pm 40.16^{*}$ & $212.07 \pm 48.26^{\Delta}$ & $<0.00 \mathrm{I}^{\mathrm{a}}$ \\
\hline TP (mg/L) & $69.88 \pm 4.43$ & $66.02 \pm 5.23^{*}$ & $62.76 \pm 4.60^{\Delta}$ & $<0.00 I^{a}$ \\
\hline ALB $(g / L)$ & $4 I .7 I \pm 3.27$ & $38.10 \pm 4.44 *$ & $38.07 \pm 3.87$ & $<0.00 \mathrm{I}^{\mathrm{a}}$ \\
\hline RBP (mg/L) & $42.96 \pm 10.12$ & $39.59 \pm 11.77$ & $40.38 \pm 12.25$ & $0.063^{\mathrm{a}}$ \\
\hline $\mathrm{Hb}(\mathrm{g} / \mathrm{L})$ & $125.45 \pm 8.73$ & $119.54 \pm 12.25 *$ & $117.33 \pm 11.83^{\Delta}$ & $<0.00 \mathrm{I}^{\mathrm{a}}$ \\
\hline
\end{tabular}

Notes: Three groups were considered: a one-way ANOVA; 'Pearson's chi-squared test; 'Kruskal-Walls test. Two groups were considered: LSD t-test (for normally distributed continuous data), chi-squared test (for categorical data), Mann-Whitney U-test (for nonnormally distributed continuous data). $* P<0.05$, prefrail vs nonfrail; $\triangle P<0.05$, frail vs nonfrail; ${ }^{\#} P<0.05$, frail vs prefrail.

Abbreviations: ADL, activities of daily living; ALB, albumin; BMI, body mass index; Hb, hemoglobin; IADL, instrumental ADL; MMSE, Mini-Mental State Examination; MNA-SF, mini nutritional assessment-short form; PA, prealbumin; POMA, performance-oriented mobility assessment; RBP, retinol-binding protein; TNF, transferrin; TP, total protein.

Table 2 Risk factors associated with frailty

\begin{tabular}{|c|c|c|}
\hline \multirow[t]{2}{*}{ Risk factors } & Frailty & \multirow[t]{2}{*}{$P$-value } \\
\hline & OR $(95 \% \mathrm{Cl})$ & \\
\hline Age & I.I87 (I.I44-I.232) & $<0.001$ \\
\hline Gender & $0.953(0.625-1.452)$ & 0.821 \\
\hline BMI & $0.985(0.933-1.040)$ & 0.585 \\
\hline Polypharmacy & $4.553(2.917-7.107)$ & 0.001 \\
\hline Fall history & $2.165(1.230-3.810)$ & 0.007 \\
\hline Grip strength & $0.878(0.85 I-0.906)$ & $<0.001$ \\
\hline Nutritional status & $3.003(1.953-4.616)$ & $<0.001$ \\
\hline TFN & $4.307(2.966-6.254)$ & $<0.001$ \\
\hline PA & $2.440(\mathrm{I} .745-3.4 \mathrm{II})$ & $<0.001$ \\
\hline TP & $3.919(2.723-5.640)$ & $<0.001$ \\
\hline ALB & $4.069(2.820-5.873)$ & $<0.001$ \\
\hline RBP & $1.528(1.129-2.067)$ & 0.006 \\
\hline $\mathrm{Hb}$ & $2.879(2.055-4.034)$ & $<0.001$ \\
\hline
\end{tabular}

Note: Each risk factor was analyzed using the univariate logistic regression analysis. Abbreviations: ALB, albumin; BMI, body mass index; Hb, hemoglobin; PA, prealbumin; RBP, retinol-binding protein; TNF, transferrin; TP, total protein. and more likely to have falls in the past year. Our results were consistent with previous findings. ${ }^{14,23,24}$ However, we found no significant difference in the educational level between groups of different frailty status, which was not consistent with previous findings. ${ }^{23,24}$ The possible reason underlying this discrepancy may be that the classification criteria of educational level in our study were different from that in the previous studies. In addition, educational level was not a direct risk factor of frailty.

The frailty status was categorized into nonfrailty, prefrailty, and frailty. Each risk factor that might be associated with frailty was analyzed using the univariate logistic regression analysis. Our study found that frailty status was positively related to age, polypharmacy, fall history, nutritional status, serum levels of TFN, PA, TP, ALB, RBP, and $\mathrm{Hb}$, but was negatively related to grip strength. The ordinal logistic regression analysis showed that older patients who were well nourished and had higher serum levels of TFN, $\mathrm{TP}$, and ALB were less likely to develop into frailty with 
Table 3 Relationship between frailty status and risk factors

\begin{tabular}{|c|c|c|c|c|c|}
\hline \multirow[t]{2}{*}{ Risk factor } & Fried score & \multirow[t]{2}{*}{ Standard error } & \multirow[t]{2}{*}{ Wald } & \multirow[t]{2}{*}{$95 \% \mathrm{Cl}$} & \multirow[t]{2}{*}{$P$-value } \\
\hline & Estimate & & & & \\
\hline Age & 0.084 & 0.020 & 17.882 & 0.045 to 0.123 & $<0.001$ \\
\hline Gender $=0$ & -0.615 & 0.351 & 3.066 & -1.304 to 0.073 & 0.080 \\
\hline Gender $=1$ & $0^{a}$ & & & & \\
\hline BMI & 0.072 & 0.033 & 4.776 & 0.007 to 0.136 & 0.029 \\
\hline Polypharmacy $=0$ & -1.244 & 0.268 & 21.547 & -1.770 to -0.719 & $<0.001$ \\
\hline Polypharmacy $=1$ & $0^{\mathrm{a}}$ & & & & \\
\hline Fall history $=0$ & -0.173 & 0.317 & 0.296 & -0.795 to 0.450 & 0.587 \\
\hline Fall history $=0$ & $0^{a}$ & & & & \\
\hline Grip strength & -0.113 & 0.022 & 27.656 & -0.155 to -0.071 & $<0.001$ \\
\hline Nutritional status $=0$ & -2.405 & 0.718 & 11.200 & -3.813 to -0.996 & 0.001 \\
\hline Nutritional status $=\mathrm{I}$ & -1.066 & 0.708 & 2.269 & -2.453 to 0.321 & 0.132 \\
\hline Nutritional status $=2$ & $0^{\mathrm{a}}$ & & & & \\
\hline $\mathrm{TFN}=0$ & -1.333 & 0.415 & 10.318 & -2.147 to -0.520 & 0.001 \\
\hline $\mathrm{TFN}=\mathrm{I}$ & -0.490 & 0.328 & 2.238 & -1.133 to 0.152 & 0.135 \\
\hline $\mathrm{TFN}=2$ & $0^{\mathrm{a}}$ & & & & \\
\hline$P A=0$ & 0.114 & 0.386 & 0.088 & -0.642 to 0.870 & 0.767 \\
\hline$P A=1$ & 0.034 & 0.295 & 0.013 & -0.543 to 0.612 & 0.908 \\
\hline$P A=2$ & $0^{\mathrm{a}}$ & & & & \\
\hline $\mathrm{TP}=0$ & -0.038 & 0.016 & 5.353 & -0.070 to -0.006 & 0.021 \\
\hline $\mathrm{TP}=\mathrm{I}$ & -0.284 & 0.329 & 0.742 & -0.930 to 0.362 & 0.389 \\
\hline $\mathrm{TP}=2$ & $0^{\mathrm{a}}$ & & & & \\
\hline$A L B=0$ & -0.952 & 0.343 & 7.710 & -1.624 to -0.280 & 0.005 \\
\hline$A L B=1$ & -0.798 & 0.428 & 3.483 & -1.637 to 0.040 & 0.062 \\
\hline$A L B=2$ & $0^{\mathrm{a}}$ & & & & \\
\hline $\mathrm{RBP}=0$ & 0.495 & 0.366 & 1.830 & -0.222 to 1.212 & 0.176 \\
\hline $\mathrm{RBP}=\mathrm{I}$ & 0.070 & 0.294 & 0.057 & -0.507 to 0.647 & 0.812 \\
\hline $\mathrm{RBP}=2$ & $0^{\mathrm{a}}$ & & & & \\
\hline $\mathrm{Hb}=0$ & -0.616 & 0.391 & 2.478 & -1.382 to 0.151 & 0.115 \\
\hline $\mathrm{Hb}=\mathrm{I}$ & -0.443 & 0.325 & 1.857 & -1.079 to 0.194 & 0.173 \\
\hline $\mathrm{Hb}=2$ & $0^{\mathrm{a}}$ & & & & \\
\hline
\end{tabular}

Notes: All data were analyzed by ordinal logistic regression analysis with adjustment for age, gender, BMI, polypharmacy, fall history, and grip strength. ${ }^{2}$ This parameter is set zero because it is redundant.

Abbreviations: ALB, albumin; BMI, body mass index; Hb, hemoglobin; PA, prealbumin; RBP, retinol-binding protein; TNF, transferrinl; TP, total protein.

adjustment of age, gender, BMI, polypharmacy, fall history, and grip strength. Previous studies have shown that there was a close relationship between nutritional status and frailty. ${ }^{14,15,25,26}$ Soysal et $\mathrm{al}^{27}$ has demonstrated that the MNA can be used to detect frailty with a sensitivity of $66.9 \%$ and a specificity of $85.4 \%$, suggesting a very close relationship between the nutritional status and frailty.

Protein-energy homeostasis is a major determinant of healthy aging. It has been shown that lower protein intake was associated with a higher frailty prevalence. ${ }^{28-31}$ Consistently, our study found that significantly higher serum levels of nutrition-related proteins were observed in the nonfrail patients compared to the prefrail and frail patients. In addition, ordinal logistic regression analysis also showed that patients with higher serum levels of TFN, TP, and ALB were less likely to develop into frailty. Although the association between serum levels of PA, RBP, Hb, and frailty was not found in our study, significant differences in these biomarkers did exist between the three groups. Deficiency of other important nutritional determinants, such as vitamin B12, is also found to be associated with frailty. ${ }^{32}$

Our study has limitations. First, our study is a crosssectional study and does not support causality conclusions. Second, generalization of our results should be cautious 
because the participants were from one hospital rather than multiple centers. Third, there are overlapping items between the frailty phenotype and MNA-SF.

\section{Conclusion}

Older hospitalized patients who were well nourished and had higher serum levels of TFN, TP, and ALB were less likely to develop into frailty. These nutrition-related biomarkers might be used for screening frailty in older patients.

\section{Acknowledgments}

Xiufang Hong was supported by funds from the Zhejiang Province Association of Traditional Chinese Medicine (2016ZB012, 2018ZA005) and the Science and Technology Department of Zhejiang Province (2018KY198). Liyu Xu was supported by a fund from the Science and Technology Department of Zhejiang Province (2017KY177).

\section{Disclosure}

The authors report no conflicts of interest in this work.

\section{References}

1. Fried LP, Hadley EC, Walston JD, et al. From bedside to bench: research agenda for frailty. Sci Aging Knowledge Environ. 2005;2005(31):pe24.

2. Lipsitz LA. Dynamics of stability: the physiologic basis of functional health and frailty. J Gerontol A Biol Sci Med Sci. 2002;57(3):B115-B125.

3. Fried LP, Tangen CM, Walston J, et al. Frailty in older adults: evidence for a phenotype. J Gerontol A Biol Sci Med Sci. 2001;56(3):M146-M157.

4. Bortz WM. The physics of frailty.JAm Geriatr Soc. 1993;41(9):1004-1008.

5. Lipsitz LA, Goldberger AL. Loss of "complexity" and aging. Potential applications of fractals and chaos theory to senescence. JAMA. 1992; 267(13):1806-1809.

6. Santos-Eggimann B, Cuénoud P, Spagnoli J, Junod J. Prevalence of frailty in middle-aged and older community-dwelling Europeans living in 10 countries. J Gerontol A Biol Sci Med Sci. 2009;64(6):675-681.

7. Mitnitski AB, Mogilner AJ, Rockwood K. Accumulation of deficits as a proxy measure of aging. ScientificWorldJournal. 2001;1:323-336.

8. Gómez Ramos MJ, González Valverde FM, Sánchez Alvarez C. [Nutritional status of an hospitalised aged population]. Nutr Hosp. 2005; 20(4):286-292.

9. Guigoz Y. The Mini Nutritional Assessment (MNA) review of the literature - what does it tell us? J Nutr Health Aging. 2006;10(6): 466-485.

10. Gentile S, Lacroix O, Durand AC, et al. Malnutrition: a highly predictive risk factor of short-term mortality in elderly presenting to the emergency department. J Nutr Health Aging. 2013;17(4):290-294.

11. Lim SL, Ong KC, Chan YH, Loke WC, Ferguson M, Daniels L. Malnutrition and its impact on cost of hospitalization, length of stay, readmission and 3-year mortality. Clin Nutr. 2012;31(3):345-350.

12. Luger E, Haider S, Kapan A, Schindler K, Lackinger C, Dorner TE. Association between nutritional status and quality of life in (Pre) frail community-dwelling older persons. J Frailty Aging. 2016;5(3): 141-148.

13. Laur CV, McNicholl T, Valaitis R, Keller HH. Malnutrition or frailty? Overlap and evidence gaps in the diagnosis and treatment of frailty and malnutrition. Appl Physiol Nutr Metab. 2017;42(5):449-458.
14. Kim J, Lee Y, Won CW, Lee KE, Chon D. Nutritional status and frailty in community-dwelling older Korean adults: the Korean frailty and aging cohort study. J Nutr Health Aging. 2018;22(7):774-778.

15. Chye L, Wei K, Nyunt MSZ, Gao Q, Wee SL, Ng TP. Strong relationship between malnutrition and cognitive frailty in the singapore longitudinal ageing studies (SLAS-1 and SLAS-2). J Prev Alzheimers Dis. 2018;5(2):142-148.

16. Mahoney FI, Barthel DW. Functional evaluation: the Barthel index. Md State Med J. 1965;14:61-65.

17. Lawton MP, Brody EM. Assessment of older people: self-maintaining and instrumental activities of daily living. Gerontologist. 1969;9(3): 179-186.

18. Lobo A, Ezquerra J, Gómez Burgada F, Sala JM, Seva Díaz A. [Cognocitive mini-test (a simple practical test to detect intellectual changes in medical patients)]. Actas Luso Esp Neurol Psiquiatr Cienc Afines. 1979;7(3):189-202.

19. Rubenstein LZ, Harker JO, Salvà A, Guigoz Y, Vellas B. Screening for undernutrition in geriatric practice: developing the short-form mini-nutritional assessment (MNA-SF). J Gerontol A Biol Sci Med Sci. 2001;56(6):M366-M372.

20. Tinetti ME, Baker DI, McAvay G, et al. A multifactorial intervention to reduce the risk of falling among elderly people living in the community. N Engl J Med. 1994;331(13):821-827.

21. Lilamand M, Kelaiditi E, Cesari M, et al. Validation of the mini nutritional assessment-short form in a population of frail elders without disability. Analysis of the toulouse frailty platform population in 2013. $J$ Nutr Health Aging. 2015;19(5):570-574.

22. Viktil KK, Blix HS, Moger TA, Reikvam A. Polypharmacy as commonly defined is an indicator of limited value in the assessment of drug-related problems. Br J Clin Pharmacol. 2007;63(2):187-195.

23. Dokuzlar O, Soysal $P$, Isik AT. Association between serum vitamin $B 12$ level and frailty in older adults. North Clin Istanb. 2017;4(1):22-28.

24. Eyigor S, Kutsal YG, Duran E, et al. Frailty prevalence and related factors in the older adult-FrailTURK Project. Age (Dordr). 2015; 37(3):9791.

25. de Jong N, Chin A, Paw MJ, de Groot LC, de Graaf C, Kok FJ, van Staveren WA. Functional biochemical and nutrient indices in frail elderly people are partly affected by dietary supplements but not by exercise. J Nutr. 1999;129(11):2028-2036.

26. Slee A, Birch D, Stokoe D. The relationship between malnutrition risk and clinical outcomes in a cohort of frail older hospital patients. Clin Nutr ESPEN. 2016;15:57-62.

27. Soysal P, Isik AT, Arik F, Kalan U, Eyvaz A, Veronese N. Validity of the mini-nutritional assessment scale for evaluating frailty status in older adults. J Am Med Dir Assoc. Epub 2018 Sep 24.

28. Bartali B, Frongillo EA, Bandinelli S, et al. Low nutrient intake is an essential component of frailty in older persons. J Gerontol A Biol Sci Med Sci. 2006;61(6):589-593.

29. Rahi B, Colombet Z, Gonzalez-Colaço Harmand M, et al. Higher protein but not energy intake is associated with a lower prevalence of frailty among community-dwelling older adults in the French three-city cohort. J Am Med Dir Assoc. 2016;17(7):672.e7-672.e11.

30. Kobayashi S, Suga H, Sasaki S; Three-generation Study of Women on Diets and Health Study Group. Diet with a combination of high protein and high total antioxidant capacity is strongly associated with low prevalence of frailty among old Japanese women: a multicenter cross-sectional study. Nutr J. 2017;16(1):29.

31. Porter Starr KN, Pieper CF, Orenduff MC, et al. Improved function with enhanced protein intake per meal: a pilot study of weight reduction in frail, obese older adults. J Gerontol A Biol Sci Med Sci. 2016;71(10): 1369-1375.

32. Ates Bulut E, Soysal P, Aydin AE, Dokuzlar O, Kocyigit SE, Isik AT. Vitamin B12 deficiency might be related to sarcopenia in older adults. Exp Gerontol. 2017;95:136-140. 


\section{Supplementary material}

Table SI Reassignment of the variables

\begin{tabular}{|c|c|c|}
\hline Variable & Group & Value \\
\hline \multirow[t]{2}{*}{ Gender } & Female & 0 \\
\hline & Male & 1 \\
\hline \multirow[t]{3}{*}{ Educational level } & High level (12 years) & 0 \\
\hline & Middle level (7-12 years) & 1 \\
\hline & Low level (0-6 years) & 2 \\
\hline \multirow[t]{2}{*}{ Polypharmacy } & Negative & 0 \\
\hline & Positive & 1 \\
\hline \multirow[t]{2}{*}{ Fall history } & Negative & 0 \\
\hline & Positive & 1 \\
\hline \multirow[t]{3}{*}{ Frail status } & Nonfrail (Fried frail index: 0) & 0 \\
\hline & Prefrail (Fried frail index: $I-2$ ) & 1 \\
\hline & Frail (Fried frail index: 3-5) & 2 \\
\hline \multirow[t]{3}{*}{ Nutritional status } & Well nourished (MNA-SF: I2-I4) & 0 \\
\hline & Risk of malnutrition (MNA-SF: 8-II) & 1 \\
\hline & Malnutrition (MNA-SF: 0-7) & 2 \\
\hline \multirow[t]{3}{*}{ TFN level } & High level (>3.36 g/L) & 0 \\
\hline & Middle level $(2.02-3.36 \mathrm{~g} / \mathrm{L})$ & 1 \\
\hline & Low level $(<2.02 \mathrm{~g} / \mathrm{L})$ & 2 \\
\hline \multirow[t]{3}{*}{ PA level } & High level (>250 mg/L) & 0 \\
\hline & Middle level (I87-250 mg/L) & 1 \\
\hline & Low level $(<187$ mg/L) & 2 \\
\hline \multirow[t]{3}{*}{ TP level } & High level (>70.8I g/L) & 0 \\
\hline & Middle level (62.57-70.8I g/L) & 1 \\
\hline & Low level $(<62.57 \mathrm{~g} / \mathrm{L})$ & 2 \\
\hline \multirow[t]{3}{*}{ ALB level } & High level (>42.56 g/L) & 0 \\
\hline & Middle level (36.24-42.56 g/L) & 1 \\
\hline & Low level $(<36.24 \mathrm{~g} / \mathrm{L})$ & 2 \\
\hline \multirow[t]{3}{*}{ RBP level } & High level (>47.40 mg/L) & 0 \\
\hline & Middle level (33.46-47.40 mg/L) & 1 \\
\hline & Low level (<33.46 mg/L) & 2 \\
\hline \multirow[t]{3}{*}{$\mathrm{Hb}$ level } & High level (>129 g/L) & 0 \\
\hline & Middle level (I I $2-129 \mathrm{~g} / \mathrm{L})$ & 1 \\
\hline & Low level $(<112 \mathrm{~g} / \mathrm{L})$ & 2 \\
\hline
\end{tabular}

Abbreviations: ALB, albumin; Hb, hemoglobin; MNA-SF, mini nutritional assessment-short form; PA, prealbumin; RBP, retinol-binding protein; TNF, transferrin; TP, total protein.

Clinical Interventions in Aging

Dovepress

\section{Publish your work in this journal}

Clinical Interventions in Aging is an international, peer-reviewed journal focusing on evidence-based reports on the value or lack thereof of treatments intended to prevent or delay the onset of maladaptive correlates of aging in human beings. This journal is indexed on PubMed Central, MedLine,
CAS, Scopus and the Elsevier Bibliographic databases. The manuscript management system is completely online and includes a very quick and fair peer-review system, which is all easy to use. Visit http://www.dovepress. com/testimonials.php to read real quotes from published authors. 